\title{
DEPENDÊNCIA DE MICORRIZAS PARA A NODULAÇÃO DE LEGUMINOSAS ARBÓREAS TROPICAIS ${ }^{1}$
}

\author{
Ederson da Conceição Jesus² ${ }^{2}$ Jolimar Antônio Schiavo³ e Sérgio Miana de Faria ${ }^{4}$
}

\begin{abstract}
RESUMO - As espécies de leguminosas Piptadenia gonoacantha e Piptadenia paniculata apresentam dificuldade para nodular e crescer em substratos esterilizados, o que dificulta a seleção de estirpes de rizóbio eficientes dessas espécies. As plantas que apresentam nódulos no campo estão micorrizadas. Assim, a boa resposta das plantas no campo pode ser devida à presença de FMAs. O objetivo deste trabalho foi estudar o efeito da micorrização sobre a nodulação e crescimento de plantas de $P$. gonoacantha e $P$. paniculata. Os experimentos foram realizados em casa de vegetação, na Embrapa Agrobiologia, Rio de Janeiro. As plantas foram inoculadas com estirpes de rizóbio específicas de cada espécie e com os fungos Gigaspora margarita e Glomus clarum. Ambas as espécies vegetais demonstraram-se altamente responsivas à inoculação com FMAs. Plantas que receberam rizóbios e fungos micorrízicos apresentaram-se noduladas, com maior produção de matéria seca. Já as plantas inoculadas apenas com rizóbio não exibiram nódulos e tiveram menor acúmulo de matéria seca. As plantas de $P$. gonoacantha apresentaram maior conteúdo de P na parte aérea quando inoculadas com FMAs. Esses resultados indicam que a micorrização é necessária para a nodulação e crescimento satisfatórios das espécies estudadas, e sugerese a inoculação com FMAs para a seleção de estirpes eficientes de rizóbio em leguminosas com dificuldade de crescimento no sistema convencional de seleção de estirpes.
\end{abstract}

Palavras-chave: Piptadenia gonoacantha, Piptadenia paniculata, dependência micorrízica, nodulação e leguminosas arbóreas.

\section{DEPENDENCE ON ARBUSCULAR MYCORRHIZAL FUNGI FOR NODULATION AND GROWTH OF TROPICAL WOODY LEGUME SPECIES}

\begin{abstract}
The leguminous species Piptadenia gonoacantha and Piptadenia paniculata do not nodulate and grow well on sterilized substrates. For this reason selection of efficient rhizobial strains for these species becomes hard to perform. Plants growing in the field are well nodulated and colonized with mycorrhizal fungi. Mycorrhizal colonization may be an explanation for the good plant responses in the field. The effect of mycorrhizal inoculation on nodulation and growth of the woody legume species $\boldsymbol{P}$. gonoacantha and $\boldsymbol{P}$. paniculata was studied. The experiments were carried out under greenhouse conditions, at Embrapa Agrobiologia, Rio de Janeiro. The species were inoculated with specific rhizobia and with the mycorrhizal fungi Gigaspora margarita and Glomus clarum. Both tree species were highly responsive to mycorrhizal inoculation. Only the plants inoculated with both rhizobium and mycorrhizal fungi were nodulated. Plants inoculated with both rhizobia and mycorrhizal fungi presented higher dry matter than those inoculated only with rhizobia. P. gonoacantha plants presented higher shoot phosphorus content when inoculated with mycorrhizal fungi. These results show that mycorrhizal inoculation is needed for nodulation and growth of the tree species studied. We suggest the use of mycorrhizal fungi to select rhizobial strains for legumes which have difficulty to grow in Leonard jars.
\end{abstract}

Keywords: Piptadenia gonoacantha, Piptadenia paniculata, mycorrhizal dependence, nodulation, woody legumes.

\footnotetext{
${ }^{1}$ Recebido em $1^{\circ} .09 .2003$ e aceito para publicação em 20.04.2005.

${ }^{2}$ Programa de Pós-Graduação em Solos e Nutrição de Plantas da UFLA.Cx.P.37, 37200-000Lavras-MG E-mail: edersonjesus@ hotmail.com.

${ }^{3}$ Programa de Pós-Graduação em Produção Vegetal da UENF/CCTA/Lsol. Av. Alberto Lamego, 2000, Parque Califórnia, 28013600 Campos dos Goytacazes RJ. E-mail: <schiavo@uenf.br>.

${ }^{4}$ Embrapa Agrobiologia. Laboratório de Leguminosas, BR 465 (Antiga Estrada Rio-São Paulo), km 47, 23890-000 Seropédica,RJ. E-mail:<sdfaria@cnpab.embrapa.br>.
} 


\section{INTRODUÇÃO}

A família Leguminosae é uma das maiores famílias botânicas, com aproximadamente 19.700 espécies (POLHILL, 1981), e essas espécies são, em sua maior parte, árvores tropicais (DÖBEREINER, 1984). Muitas leguminosas conhecidas são capazes de formar nódulos com bactérias fixadoras de nitrogênio e têm potencial para uso em sistemas agroflorestais, para reabilitação de áreas degradadas e para ajudar a manutenção da sustentabilidade dos solos (HERRERA et al., 1993; FRANCO e FARIA, 1997).

Para que a utilização dessas espécies seja bemsucedida, é necessário utilizar estirpes de rizóbio eficientes na fixação de $\mathrm{N}_{2}$ (FBN). A seleção dessas estirpes é uma etapa fundamental para a produção de inoculantes comerciais, e a inoculação com estirpes eficientes é importante para o melhor desenvolvimento das plantas no campo. Normalmente, essa seleção é realizada inicialmente em substratos esterilizados, em vasosde-Leonard, que constituem um sistema de seleção de grande eficiência (VINCENT, 1970; GIBSON, 1987). Porém, algumas espécies de leguminosas arbóreas, como as dos gêneros Parapiptadenia e Piptadenia, apresentam problemas de desenvolvimento nesse sistema, dificultando o trabalho de seleção de estirpes (FARIA, 1995). No campo, as plantas dessas espécies se apresentam colonizadas por fungos micorrízicos arbusculares (FMAs), e esta pode ser uma razão para o desenvolvimento satisfatório e para a boa nodulação dessas espécies nessas condições.

Os efeitos dos FMAs sobre o crescimento e a nodulação de leguminosas já são bem conhecidos (BAREAeAZCÓN-AGUILAR, 1983; CARDOSO, 1985; CARDOSO, 1986; SILVEIRA e CARDOSO, 1987; GUZMAN-PLAZOLA e FERRERA-CERRATO, 1990). Segundo Barea et al. (1992), o principal papel do fungo são o fornecimento de $\mathrm{P}$ para a planta hospedeira e o suprimento da alta demanda desse nutriente para os nódulos. O processo de FBN é altamente exigente em energia na forma de ATP, de modo que o adequado suprimento de $\mathrm{P}$ proporcionado pelo FMA beneficia esse processo. As espécies Acacia mangium, Acacia auriculiformis (DE LA CRUZ et al., 1988), Albizia lebeck (FARIA et al., 1995a), Centrolobium tomentosum (MARQUES et al., 2001) e Anadenathera peregrina (GROSS et al., 2004) são exemplos de leguminosas que apresentam melhor desenvolvimento e nodulação quando inoculadas com FMAs.
As espécies vegetais exibem diferentes graus de dependência micorrízica (SIQUEIRA e SAGIN-JÚNIOR, 2001). Algumas são altamente dependentes, de modo que o efeito benéfico do FMA é observado mesmo em níveis elevados de $\mathrm{P}$ no solo. Desse modo, a presença do FMA pode ser essencial para uma boa nodulação, a qual é importante para a seleção de estirpes de rizóbios eficientes na FBN. Assim, este trabalho teve por objetivo estudar a dependência de micorrizas para a nodulação e crescimento de Piptadenia gonoacantha (Mart.) Macbr. e Piptadenia paniculata Bentham, duas espécies de leguminosas arbóreas nativas da Região Sudeste do Brasil e com potencial para serem utilizadas em programas de revegetação.

\section{MATERIAL E MÉTODOS}

Foram realizados dois experimentos em casa de vegetação, na Embrapa Agrobiologia, com as espécies Piptadenia gonoacantha (Mart.) Macbr. e Piptadenia paniculata Bentham.

Os experimentos foram montados no esquema fatorial com tratamentos adicionais $2 \times 2+3$. Os fatores foram estirpe de rizóbio e inoculação com fungos micorrízicos arbusculares (FMAs). O fator estirpe de rizóbio se subdividiu em dois níveis, de acordo com o número de estirpes utilizadas e o fator inoculação com FMAs, nos níveis presença ou ausência de FMAs. Os tratamentos adicionais foram as testemunhas com nitrogênio mineral ( $\mathrm{N}$ mineral), com $\mathrm{N}$ mineral e FMAs (N mineral + FMA) e sem inoculação e adubação com $\mathrm{N}$ mineral (T). O delineamento experimental foi em blocos casualizados, com três repetições.

Foram utilizadas as estirpes de rizóbio BR3452 e BR4812 para P. gonoacantha e BR4829 e BR3405 para P. paniculata. O inoculante de FMAs utilizado consistiu de uma mistura de solo, esporos e raízes de Brachiaria decumbens colonizadas com os fungos micorrízicos Gigaspora margarita Becker \& Hall e Glomus clarum Nicolson \& Schenck.

Os experimentos foram realizados em vasos de polietileno com $4 \mathrm{~kg}$ de solo e areia misturados na proporção $1: 1(\mathrm{v}: \mathrm{v})$. Esse substrato apresentou as

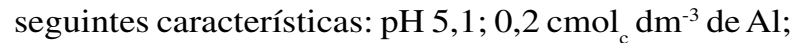
$3,2 \mathrm{cmol}_{\mathrm{c}} \mathrm{dm}^{-3} \mathrm{de} \mathrm{Ca} ; 1,5 \mathrm{cmol}_{\mathrm{c}} \mathrm{dm}^{-3} \mathrm{de} \mathrm{Mg} ; 4 \mathrm{mg} \mathrm{dm}^{-3}$ de P; e $61 \mathrm{mg} \mathrm{dm}^{-3}$ de K. O substrato foi adubado com $5,5 \mathrm{~g}$ de fosfato de rocha Araxá/kg e, posteriormente, autoclavado duas vezes, por $2 \mathrm{~h}$, sendo, então, transferido 
para os vasos de polietileno. As sementes de $P$. gonoacantha foram desinfestadas com hipoclorito de sódio $0,5 \%$, por $10 \mathrm{~min}$, e as sementes de $P$. paniculata foram desinfestadas com hipoclorito de sódio 5\%, por $5 \mathrm{~min}$. As sementes foram pré-germinadas em bandejas com areia e vermiculita autoclavadas e transferidas para os vasos após a emissão das radículas. Juntamente com as sementes foram adicionados $1 \mathrm{~mL}$ do inoculante de rizóbio e $10 \mathrm{~g} /$ planta do inoculante de FMAs, nas plantas de $P$. gonoacantha, e $1 \mathrm{~mL}$ do inoculante de rizóbio e $15 \mathrm{~g} /$ planta do inoculante de FMAs, nas plantas de $P$. paniculata.

As testemunhas com nitrogênio dos dois experimentos receberam, semanalmente, a aplicação de $10 \mathrm{mg}$ de $\mathrm{N}$, sob a forma de nitrato de amônio $\left(\mathrm{NH}_{4} \mathrm{NO}_{3}\right)$. Os experimentos com $P$. gonoacantha e $P$. paniculata foram colhidos com 151 e 259 dias, respectivamente.

As características avaliadas nos dois experimentos foram matéria seca da parte aérea, das raízes e dos nódulos, número de nódulos e colonização micorrízica. Adicionalmente, no experimento com P. gonoacantha também foi determinado o conteúdo de $\mathrm{P}$ na parte aérea das plantas.

A parte aérea, raízes e nódulos das plantas foram coletados, secados a $65^{\circ} \mathrm{C}$ e pesados para determinação do acúmulo de matéria seca. A colonização micorrízica foi avaliada em amostras de raízes finas clarificadas e coradas, de acordo com o método utilizado por Koske e Gemma (1989), e a taxa de colonização micorrízica foi estimada pelo método de interseção em placa quadriculada de Giovannetti e Mosse (1980). A resposta das plantas às micorrizas foi calculada através da fórmula de Plenchette et al. (1983), com base na matéria seca total acumulada pelos tratamentos inoculados com rizóbio e FMAs e pelos tratamentos inoculados apenas com rizóbio. A eficiência e a eficácia da inoculação foram determinadas com a utilização das seguintes fórmulas: eficiência $=$ (matéria seca do tratamento/matéria seca do tratamento $\mathrm{T}) \mathrm{X} 100$; eficácia $=($ matéria seca do tratamento/matéria seca do tratamento $\mathrm{N}$ mineral + FMA)X100. O P na parte aérea de $P$. gonocantha foi analisado de acordo com a metodologia apresentada por Silva (1999). Os dados de matéria seca foram transformados para raiz quadrada [log(variável)], para se obterem a normalidade e a homocedasticidade dos dados, e submetidos à análise de variância e ao teste de Duncan a $5 \%$ de probabilidade, com o auxílio do programa SAEG (Universidade Federal de Viçosa). Os dados de colonização micorrízica foram classificados de acordo com a classificação apresentada por Carneiro et al. (1998), em que a colonização micorrízica é considerada baixa quando menor que $20 \%$, média quando variando de 20 a $50 \%$ e alta quando maior que $50 \%$.

\section{RESULTADOS}

A produção de matéria seca da parte aérea (MSPA) e das raízes (MSR) de $P$. gonoacantha foi semelhante nas plantas dos tratamentos BR3452+FMA e BR4812+FMA, inoculadas simultaneamente com rizóbios e FMAs, e maior que a produção de matéria seca das plantas dos tratamentos BR3452 e BR4812, inoculadas apenas com rizóbio (Figura 1). Consequientemente, os tratamentos inoculados simultaneamente com rizóbio e FMAs apresentaram alta eficiência e eficácia na promoção do crescimento das plantas (Tabela 1). As plantas inoculadas dos tratamentos BR3452 e BR4812 não nodularam (Tabela 1) e apresentaram um acúmulo de MSPA e MSR semelhante ao da testemunha sem inoculação e adubação mineral (T) (Figura 1). Dessa forma, a eficiência e a eficácia desses tratamentos foram baixas (Tabela 1 ).

Resposta semelhante foi observada no experimento com $P$. paniculata. As plantas dos tratamentos BR3405+FMA e BR4829+FMA apresentaram maior produção de MSPAe MSR que as plantas dos tratamentos BR3405 e BR4829 (Figura 2), e a eficiência e a eficácia dos tratamentos duplamente inoculados foram elevadas (Tabela 2). As plantas dos tratamentos BR3405 e BR4829 não nodularam e apresentaram baixa eficiência e eficácia.

A produção de matéria seca na parte aérea das plantas inoculadas simultaneamente com rizóbios e FMAs de ambas as espécies foi estatisticamente semelhante à produção das plantas da testemunha $\mathrm{N}$ mineral + FMA, embora a dupla inoculação tenha proporcionado maior acúmulo de matéria seca (Figuras 1 e 2). As plantas dos tratamentos BR3452+FMA e BR4812+FMA de $P$. gonoacantha apresentaram, respectivamente, um acúmulo de matéria seca da parte aérea 60 e 74\% maior que as plantas da testemunha $\mathrm{N}$ mineral + FMA (Tabela 1) e as dos tratamentos BR3405+FMAe BR4829+FMAde P. paniculata exibiram um acúmulo superior a $100 \%$ em relação àquelas da testemunha N mineral + FMA (Tabela 2).

R. Árvore, Viçosa-MG, v.29, n.4, p.545-552, 2005 


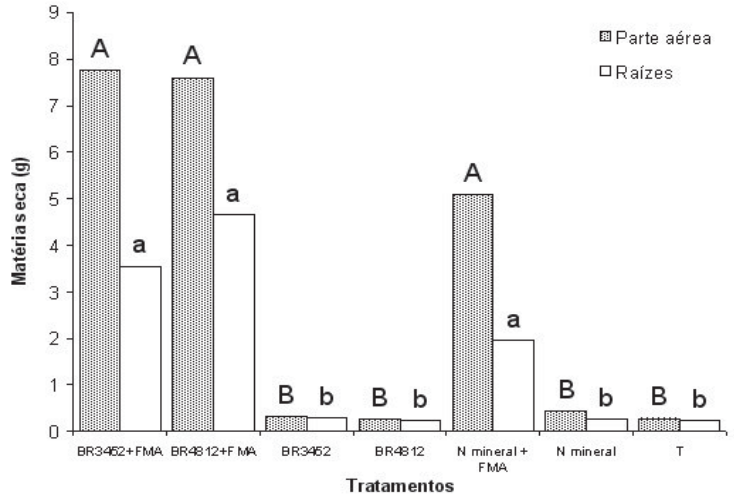

Figura 1 - Matéria seca da parte aérea e raízes de plantas de Piptadenia gonoacantha. BR3452: planta inoculada com a estirpe de rizóbio BR3452, BR4812: planta inoculada com a estirpe de rizóbio BR4812; BR3452+FMA: planta inoculada com estirpe BR3452 e FMA; BR4812+FMA: planta inoculada com estirpe BR4812 e FMA; N mineral: planta que recebeu N mineral; $\mathrm{N}$ mineral + FMA: planta com $\mathrm{N}$ mineral e inoculada com FMA; T: planta sem inoculação e sem N mineral. Média de três repetições. Tratamentos com letras iguais não diferem entre si, pelo teste de Duncan a $5 \%$ de probabilidade. Parte aérea, $\mathrm{CV}=2,057 \%$ e raízes, $\mathrm{CV}=3,363 \%$.

Figure 1 - Shoot and root dry matter of Piptadenia gonoacantha. BR3452: plant inoculated with the rhizobium strain BR3452; BR4812: plant inoculated with the rhizobium strain BR4812; BR3452+FMA: plant inoculated with the strain BR3452 and arbuscular mycorrhizal fungi (FMA); BR4812+FMA: plant inoculated with the strain BR4812 and FMA; Nmineral: plant with mineral $N$; N mineral + FMA: plant with mineral N and FMA; T: plant non-inoculated and without mineral N. Mean of 3 replicates. Treatments with the same letter are not different by the Duncan's test at $P=0.05$. Shoot, $C V=2.057 \%$; Roots, $C V=3.363 \%$.

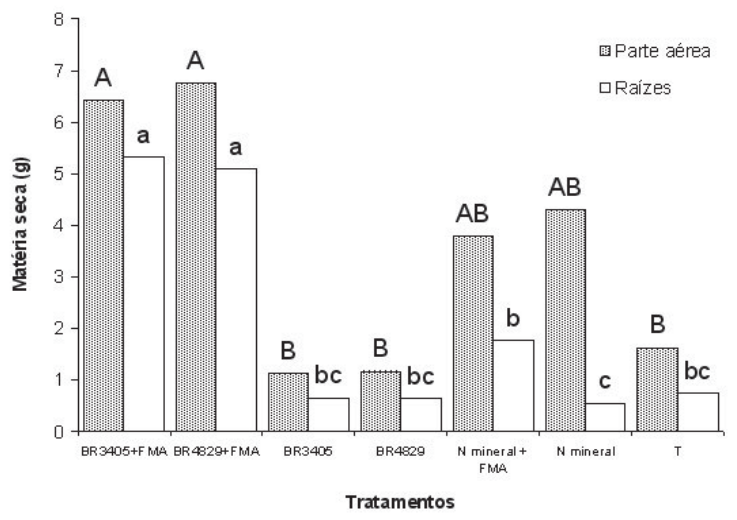

Figura 2 - Matéria seca da parte aérea e raízes de plantas de Piptadenia paniculata. BR3405: planta inoculada com a estirpe de rizóbio BR3405; BR4829: planta inoculada com a estirpe de rizóbio BR4829; BR3405 + FMA: planta inoculada com estirpe BR3405 e FMA; BR4829+FMA: planta inoculada com estirpe BR4829 e FMA; N mineral: planta que recebeu $\mathrm{N}$ mineral; N mineral + FMA: planta com N mineral e inoculada com FMA; e T: planta sem inoculação e sem $\mathrm{N}$ mineral. Média de três repetições. Tratamentos com letras iguais não diferem entre si, pelo teste de Duncan a $5 \%$ de probabilidade. Parte aérea, $C V=4,751 \%$; e raízes, $C V=3,694 \%$.

Figure 2 - Shoot and root dry matter of Piptadenia paniculata. BR3405: plant inoculated with the rhizobium strain BR3405; BR4829: plant inoculated with the rhizobium strain BR4829; BR3405+FMA: plant inoculated with the strain BR3405 and arbuscular mycorrhizal fungi (FMA); BR4829+FMA: plant inoculated with the strain BR4829 and FMA; N mineral: plant with mineral $N$; N mineral + FMA: plant with mineral $N$ and FMA; T: plant non-inoculated and without mineral N. Mean of 3 replicates. Treatments with the same letter are not different by the Duncan's test at $P=0.05$. Shoot, $C V=4.751 \%$; Roots, $C V=3.694 \%$.

Tabela 1 - Matéria seca de nódulos, taxa de colonização micorrízica, eficiência e eficácia de diferentes tratamentos sobre o crescimento Piptadenia gonoacantha

Table 1 - Dry matter of nodules, mycorrhizal colonization rate, efficiency and efficacy of different treatments on of Piptadenia gonoacantha growth

\begin{tabular}{lcccc}
\hline Tratamento & Matéria Seca de Nódulos & Colonização Micorrízica & Eficiência $^{2}$ & Eficácia $^{3}$ \\
\hline BR3452 + FMA & 73,67 & 50 & 2239 & 160 \\
BR4812 + FMA & 3,33 & 51 & 2430 & 174 \\
BR3452 & 0 & 0 & 120 & 89 \\
BR4812 & 0 & 0 & 97 & 72 \\
N mineral + FMA & 0 & 44 & 1398 & 100 \\
N mineral & 0 & 0 & 100 & - \\
T & 0 & 0 & - \\
\hline
\end{tabular}

${ }^{1}$ BR3452: planta inoculada com a estirpe de rizóbio BR3452; BR4812: planta inoculada com a estirpe BR4812; BR3452 + FMA: planta inoculada com estirpe BR3452 e FMA; BR4812 + FMA: planta inoculada com estirpe BR4812 e FMA; N mineral: planta com N mineral; $\mathrm{N}$ mineral + FMA: planta com N mineral e inoculada com FMA; e T: planta sem inoculação e sem $\mathrm{N}$ mineral. ${ }^{2}$ Eficiência $=(\mathrm{MS}$ tratamento/ MS tratamento T) X 100. ${ }^{3}$ Eficácia $=($ MS tratamento/MS tratamento N mineral + FMA) X 100.

R. Árvore, Viçosa-MG, v.29, n.4, p.545-552, 2005 
Tabela 2 - Matéria seca de nódulos, taxa de colonização micorrízica, eficiência e eficácia de diferentes tratamentos sobre o crescimento de Piptadenia paniculata

Table 2 - Dry matter of nodules, mycorrhizal colonization rate, efficiency and efficacy of different treatments on Piptadenia paniculata growth

\begin{tabular}{lcccc}
\hline Tratamento $^{1}$ & Matéria Seca de Nódulos & Colonização Micorrízica & Eficiência $^{2}$ & Eficácia $^{3}$ \\
\hline BR3405+FMA & 219 & 44 & 497 & 211 \\
BR4829+FMA & 76 & 49 & 501 & 213 \\
BR3405 & 0 & 0 & 75 & 37 \\
BR4829 & 0 & 0 & 77 & 38 \\
N mineral + FMA & 0 & 16 & 235 & 100 \\
N mineral & 0 & 0 & 206 & - \\
T & 0 & 0 & 100 & - \\
\hline
\end{tabular}

${ }^{1}$ BR3405: planta inoculada com a estirpe de rizóbio BR3405; BR4829: planta inoculada com a estirpe BR4829; BR3405 + FMA: planta inoculada com estirpe BR3405 e FMA; BR4829 + FMA: planta inoculada com estirpe BR4829 e FMA; N mineral: planta com N mineral; $\mathrm{N}$ mineral + FMA: planta com $\mathrm{N}$ mineral e inoculada com FMA; T: planta sem inoculação e sem $\mathrm{N}$ mineral. ${ }^{2}$ Eficiência $=(\mathrm{MS}$ tratamento/ MS tratamento $\mathrm{T}) \mathrm{X} 100 .{ }^{3}$ Eficácia $=($ MS tratamento/MS tratamento $\mathrm{N}$ mineral + FMA $) \mathrm{X} 100$.

Não houve diferença entre as plantas dos tratamentos BR3452+FMA e BR4812+FMA, de $P$. gonoacantha, e as plantas da testemunha com $\mathrm{N}$ mineral + FMA com respeito a MSR (Figura 1). Já as plantas dos tratamentos BR3405+FMA e BR4829+FMA de $P$. paniculata apresentaram maior acúmulo de MSR quando comparadas com às plantas da testemunha com $\mathrm{N}$ mineral + FMA (Figura 2).

Os valores de colonização micorrízica para as espécies estudadas variaram de baixo a alto (Tabelas 1 e 2), de acordo com a classificação utilizada por Carneiro et al. (1998). A colonização foi, em geral, média nas plantas de $P$. gonoacantha, sendo um pouco maior nas plantas do tratamento BR4812+FMA (Tabela 1). A colonização nas plantas de $P$. paniculata foi baixa para a testemunha com $\mathrm{N}$ mineral + FMA e média nas plantas dos demais tratamentos inoculados com FMAs (Tabela 2).

A resposta à colonização micorrízica foi alta nas duas espécies estudadas, quando calculada através da fórmula de Plenchette et al. (1983). A resposta à colonização foi de $92 \%$ para $P$. gonoacantha e de $83 \%$ para $P$. paniculata (Tabelas 1 e 2). As plantas de $P$. gonoacantha inoculadas com FMAs apresentaram maior teor de P na parte aérea do que aquelas não-inoculadas, mostrando o efeito benéfico do fungo no fornecimento de $\mathrm{P}$ às plantas (Figura 3 ).

\section{DISCUSSÃO}

A ocorrência de nodulação apenas nos tratamentos inoculados com FMAs evidencia a necessidade da micorrização para a nodulação de $P$. gonoacantha e $P$. paniculata, e o maior acúmulo de matéria seca nos tratamentos inoculados com FMAs evidencia o papel benéfico desses fungos na nutrição mineral dessas espécies.

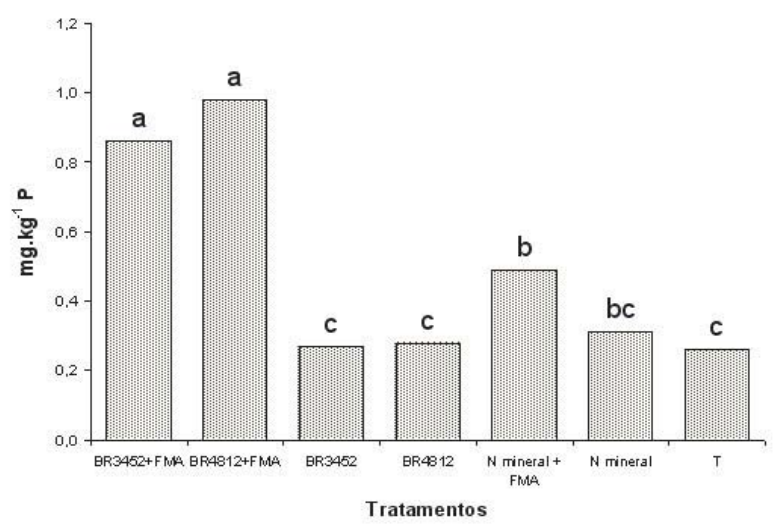

Figura 3 - Teor de P na parte aérea de plantas de Piptadenia gonoacantha. BR3452: planta inoculada com a estirpe de rizóbio BR3452; BR4812: planta inoculada com a estirpe de rizóbio BR4812; BR3452 +FMA: planta inoculada com estirpe BR3452 e FMA; BR4812 + FMA: planta inoculada com estirpe BR4812 e FMA; $\mathrm{N}$ mineral: planta que recebeu $\mathrm{N}$ mineral; $\mathrm{N}$ mineral +FMA: planta com $\mathrm{N}$ mineral e inoculada com FMA e; T: planta sem inoculação e sem $N$ mineral. Média de três repetições. Tratamentos com letras iguais não diferem entre si, pelo teste de Duncan a 5\% de probabilidade. $\mathrm{CV}=22,27 \%$.

Figure 3 - Shoot P content of Piptadenia gonoacantha. BR3452: plant inoculated with the rhizobium strain BR3452; BR4812: plant inoculated with the rhizobium strain BR4812; BR3452+FMA: plant inoculated with the strain BR3452 and arbuscularmycorrhizal fungi (FMA); BR4812+FMA: plant inoculated with the strain BR4812 and FMA; N mineral: plant with mineral $N$; Nmineral + FMA: plant with mineral Nand FMA; T: plant noninoculated and without mineral N. Mean of 3 replicates. Treatments with the same letter are not different by the Duncan's test at $P=0.05$.

R. Árvore, Viçosa-MG, v.29, n.4, p.545-552, 2005 
P. gonoacantha e $P$. paniculata são espécies pioneiras (CARVALHO, 1994) e as simbioses com rizóbios e FMAs podem fornecer-lhes vantagem competitiva, favorecendo o seu estabelecimento no ambiente. Isso é muito importante, principalmente no estágio inicial de crescimento, como é o caso das plantas dos experimentos apresentados, para a utilização dessas espécies de leguminosas para a revegetação de áreas degradadas (FRANCO e FARIA, 1997; FRANCO et al., 2000). A realização de simbioses com rizóbios e FMAs torna interessante a utilização dessas leguminosas para a revegetação de áreas degradadas, visto que essas simbioses permitem às plantas obterem os dois nutrientes mais limitantes do crescimento vegetal, o $\mathrm{N}$ e o $\mathrm{P}$ (FRANCO e FARIA, 1997).

Verificou-se que a micorrização foi necessária para a absorção de P pela $P$. gonoacantha. As plantas de $P$. gonoacantha inoculadas com FMAs apresentaram maior acúmulo de $\mathrm{P}$ na parte aérea do que aquelas não inoculadas com FMAs (Figura 2). O processo de fixação biológica de nitrogênio é um processo altamente exigente em energia na forma de ATP, de modo que o adequado suprimento de $\mathrm{P}$ fornecido pelo FMA beneficia esse processo (BAREAe AZCÓN-AGUILAR, 1983; BAREA et al., 1992). Algumas plantas, mesmo na presença de P, necessitam do auxílio do FMA para a absorção desse elemento (SIQUEIRA e SAGGIN-JÚNIOR, 2001), e a resposta de algumas leguminosas arbóreas à inoculação com FMAs pode ser verificada mesmo em solo adubado com P(FARIA et al., 1995a; FARIA et al., 1996). O melhor crescimento de $P$. gonoacantha no tratamento com $\mathrm{N}$ mineral + FMA quando este é comparado com o que recebeu somente $\mathrm{N}$ mineral pode ser atribuído ao benefício do fungo micorrízico na absorção de P. Ao favorecer a absorção de $\mathrm{P}$, o fungo micorrízico possibilitou que houvesse resposta de crescimento ao $\mathrm{N}$ aplicado à planta (Figura 1). Também é possível que o fungo tenha contribuído para a absorção de parte do $\mathrm{N}$ aplicado. $\mathrm{O}$ aumento da resposta à adubação com $\mathrm{N}$ mineral já foi observado em algumas espécies de leguminosas arbóreas inoculadas com FMAs (FARIA et al., 1995a; FARIA et al., 1995b; FARIA et al., 1996).

Os resultados obtidos comprovam que a micorrização tem papel importante para a nodulação de $P$. gonoacantha e $P$. paniculata. Dessa forma, a ausência de FMAs pode dificultar a avaliação da nodulação destas e de outras espécies de comportamento semelhante. A nodulação é uma característica importante para a seleção de estirpes de rizóbio mais eficientes. Porém, essa característica, bem como o crescimento de algumas espécies de leguminosas, são prejudicados sob o sistema de seleção convencional, em vasos-deLeonard. A inoculação com FMAs, juntamente com rizóbios, pode ser uma alternativa para a seleção de estirpes de rizóbio eficientes na fixação de nitrogênio para essas espécies. A micorrização pode permitir que os isolados de rizóbio testados em ensaios de seleção de estirpes expressem sua potencialidade ao favorecer um melhor desenvolvimento e uma melhor nodulação das plantas.

\section{CONCLUSÃO}

As espécies Piptadenia gonoacantha (Mart.) Mcbr. e Piptadenia paniculata Bentham dependem da micorrização para um crescimento satisfatório e para a nodulação com rizóbios.

\section{AGRADECIMENTOS}

Ao CNPq, pela concessão da bolsa de iniciação científica ao aluno Ederson da Conceição Jesus; à pesquisadora Eliane Maria Ribeiro da Silva, da Embrapa Agrobiologia, pelo auxílio com FMAs e pelas discussões; à pesquisadora Janaína Ribeiro Costa, pelo auxílio nas análises estatísticas; e aos técnicos dos Laboratórios de Micorrizas e Leguminosas, pela colaboração na condução dos experimentos.

\section{REFERÊNCIAS BIBLIOGRÁFICAS}

BAREA, J. M. et al. Vesicular-arbuscular mycorrhizal fungi in nitrogen fixing systems. In: NORRIS, J. R.; READ, D. J.; VARMA, A. K. (Eds.). Methods in microbiology: Techniques for the study of Mycorrhizae. London: Academic Press, 1992. v. 24. p.391-416.

BAREA, J. M.; AZCÓN-AGUILAR, C. Mycorrhizas and their significance in nodulating nitrogenfixing plants. Advances in Agronomy, v. 36, p. $1-54,1983$.

CARDOSO, E. J. B. N. Efeito de micorriza vesículo-arbuscular e fosfato-de-rocha na simbiose Soja-Rhizobium. Revista Brasileira de Ciência do Solo, v. 9, p. 125-130, 1985. 
CARDOSO, E. J. B. N. Eficiência de fungos micorrízicos vesículo-arbusculares em soja, com Rhizobium japonicum e fosfato de rocha, em função do tipo de solo. Revista Brasileira de Ciência do Solo, v. 10, p. 17-23, 1986.

CARNEIRO, M. A. C. et al. Micorriza arbuscular em espécies arbóreas e arbustivas nativas de ocorrência no sudeste do Brasil. Cerne, v. 4, n. 1, p. 129-145, 1998.

CARVALHO, P.E.R. Espécies florestais brasileiras - Recomendações silviculturais, potencialidades e uso da madeira. Colombo: Embrapa - CNPF/SPI, 1994. 640p.

DELA CRUZ, R. E. et al. Growth of trees inoculated with VA mycorrhizal fungi and Rhizobium. Plant and Soil, v. 108, p. 111-115, 1988.

DÖBEREINER, J. Nodulação e fixação de nitrogênio em leguminosas florestais. Pesquisa Agropecuária Brasileira, p. 83-90, 1984. (Edição Especial).

FARIA, M. P. et al. Crescimento de leguminosas arbóreas em resposta a fósforo, nitrogênio, fungo micorrízico e rizóbio. I. Albizia lebbeck (L.) Benth. Revista Árvore, v. 19, n. 3, p. 293-307, 1995a.

FARIA, M. P. et al. Crescimento de leguminosas arbóreas em resposta a fósforo, nitrogênio, fungo micorrízico e rizóbio. II. Peltophorum dubium (Spreng.) Taub. Revista Árvore, v. 19, n.4, p. 433-446, 1995 b.

FARIA, M. P. et al. Crescimento inicial de acácia em resposta a fósforo, nitrogênio, fungo micorrízico e rizóbio. Revista Brasileira de Ciência do Solo, v.20, p. 209-216, 1996.

FARIA, S. M. Occurrence and rhizobial selection for legume trees adapted to acid soils. In: EVANS, D. O.; SZOTT, T. (Eds.). Nitrogen fixing trees for acid soil. Hawaii: Nitrogen Fixing Tree Association, 1995. p. 295-300.
FRANCO, A. A. et al. The importance of biological nitrogen fixation on land rehabilitation. In: PEDROSA, F. O. et al. (Eds.). Nitrogen fixation: from molecules to crop productivity. New York, Kluwer Academic Publishers, 2000. p. 569-570.

FRANCO, A. A.; FARIA, S. M. The contribution of $\mathrm{N}_{2}$-fixing tree legumes to land reclamation and sustainability in the tropics. Soil Biology and Biochemistry, v. 29, n. 5/6, p. 897-903, 1997.

GIBSON, A. L. Evaluation of nitrogen fixation by legumes in the greenhouse and growth chamber. In: ELKAN, H. (Ed). Symbiotic nitrogen fixation technology. New York: Marcel Dekker, 1987. p. 321-369.

GIOVANNETTI, M.; MOSSE, B. An evaluation of techniques to measure vesicular-arbuscular mycorrhizal infection in roots. New Phytologist, v. 84, p. 489-490, 1980.

GROSS, E.; CORDEIRO, L.; CAETANO, F. H. Nodulação e micorrização em anadenanthera peregrina var. falcata em solo de cerrado autoclavado e não autoclavado. Revista Brasileira de Ciência do Solo, v. 28, p. 95-101, 2004.

GUZMAN-PLAZOLA, R. A.; FERRERA-CERRATO, $R$. La endomicorriza vesiculoarbuscular en las leguminosas. Montecillo: Colegio de Postgraduados, 1990. 122p.

HERRERA, M. A.; SALAMANCA, C. P.; BAREA, J. M. Inoculation of woody legumes with selected arbuscular mycorrhizal fungi and rhizobia to recover desertified mediterranean ecosystems. Applied Environmental Microbiology, v. 59, n. 1, p. 129-133, 1993.

KOSKE, R. E.; GEMMA, J. N. A modified procedure for staining roots to detect VA mycorrhizas. Mycology Research, n. 92, p. 488-505, 1989.

MARQUES, M. S.; PAGANO, M.; SCOTTI, M. R. M. M. L.. Dual inoculation of a woody legume (Centrolobium tomentosum) with rhizobia and mycorrhizal fungi in south-eastern Brazil.

Agroforestry Systems, v. 52, p. 107-117, 2001.

R. Árvore, Viçosa-MG, v.29, n.4, p.545-552, 2005 
PLENCHETTE, C.; FORTIN, J. A.; FURLAN, V. Growth of several plant species to mycorrhizae in a soil of moderate P-fertility. Plant and Soil, n. 70, p. 199-209, 1983.

POLHILL, R. M. The Papilionoideae. In: POLHILL, R. M.; RAVEN, P. H. (Eds.). Advances in Legume Systematics. Part 1.1. Kew: Royal Botaniic Gardens, 1981. p. 191-204.

SILVA, F. C. Manual de análises químicas de solos, plantas e fertilizantes. Brasília: Embrapa Comunicação para Transferência de Tecnoilogia, 1999. 370p.
SILVEIRA, A. P. D.; CARDOSO, E. J. B. N. Influência do tipo de solo e do fungo micorrízico vesículo-arbuscular no desenvolvimento de três cultivares de feijão. Revista Brasileira de Ciência do Solo, v. 11, p. 37-43, 1987.

SIQUEIRA, J. O.; SAGGIN-JÚNIOR, O. J. Dependency on arbuscular mycorrhizal fungi and responsiveness of some Brazilian native woody species. Mycorrhiza, v. 11, p. 245-255, 2001.

VINCENT, J. M. A manual for the practical study of root-nodule bacteria. Oxford: Blackwell Scientific Publications, 1970. (International Biological Programme Handbook, 15). 